\title{
Interactivity and Information- Communication Technologies in Chemical Engineering Classes
}

\author{
A. J. Santiago'1, C. E. da Silva1, A. F. Machado', M. G. Muniz Washington² \\ ${ }^{1}$ Department of Quantum Electronics, University of Stateof Rio de Janeiro, Rio de Janeiro, Brazil \\ ${ }^{2}$ Engineering College, University of Stateof Rio de Janeiro, Rio de Janeiro, Brazil \\ Email: aajsantiago@uol.com.br, claudio.elias13@gmail.com, alanfmac@gmail.com, gmw@superig.com.br
}

Received December 2014

\begin{abstract}
In this paper, we propose a new contextualization of the so-called scientific method in teaching practices in science and engineering education. We report an objectification in information and communication technologies (ICT) for simulate the reaction rates during an class and its inclusion in the above-mentioned pedagogical purpose, that, in tune with the current realities of schools, rehearses reflections of a future with another horizon for teaching/learning engineering and other sciences.
\end{abstract}

Keywords

Methodology, Science Education, Teaching and Learning

\section{Introduction}

The basic goal of engineering is to establish physical models of the world around us and what is useful to the development of any project. In order to achieve these goals, the engineer shall be provided with training in the exact sciences, with the necessary basic knowledge of the science involved, so they can develop a routine for calculating and recognizing the technical limitations of the formulas and computer programs: the project activity.

Unfortunately, it is increasingly clear that the teaching of engineering still depends excessively on the teaching methods used in the past with courses backed on lectures, assignments in rigidly defined, highly fragmented and individualized problems. But the teaching of the most important technical skills of engineering, i.e. the integration of knowledge, synthesis, design and innovation, go far beyond the learning. As a recent National Science Board (NSB) workshop puts it: "The ubiquitous lecture is the bane of true learning, especially in observation-based, hands-on fields such as engineering." [1].

The system overruled by lecture classes is a naturally passive learning environment. Engineering education must move away from the current field of pedagogy in the classroom, adopting more active learning approaches that enable greater interactivity, involving problem-solving skills and team building. Endorsing this view, Bordogna cites the ancient Chinese proverb: "I hear and I forget. I see and I remember. I do and I understand.” [2]. 
Unfortunately, even nowadays, engineering students have little opportunity for learning experiences, guided discoveries and interactive/collaborative practices. The most used educational resources in the majority of schools are books and copybooks, despite all the limitations that may follow them and the fact that they no longer arouse interest among the participants [3]. In contrast, the interest of students with certain educational resources, such as computers and practice or experimental classes, is well known [4]. In particular, it has been reported the successful the teaching of physics through educational games [5].

On the other hand, observation, reflection and experimentation are the steps (not necessarily in this order) which compose the so-called scientific method. In general, the scientific method meets the fundamental instruments for conducting analytical reasoning of the subject in relation to its subject matter. This reasoning has to be developed in a systematic and orderly manner, so that the scientist can achieve the goal of your research project: the study of a phenomenon. So, the scientific method articulates the essential instrumental procedures for the construction of knowledge, producing the body of knowledge that constitutes science. Then, we deduce the relevance of the scientific method in pedagogical practice in school, as once the scientific methodology and the methodology of teaching engineering and science are well-articulated, the process of teaching and learning can be developed consistently and guarantee the fixing of the worked contents.

The traditional classroom paradigm is being challenged today, not so much by teachers who have, in general, their teaching efforts optimized for a lecture format, but by students. Now, students have already been born into a digital world and are comfortable with these technologies. Their lives are immersed in electronic games, video media, personal computers, mobile phones, instant messaging, etc. Unlike us, who were raised in an era of passive media, whose agents were broadcast radio and television, today's students expect, and in fact, look for interaction. They conceive learning as a "plug-and-play" experience. They are neither accustomed to, nor willing to learn sequentially, by reading the manual.

In fact, today's students are active learners. They are adept to multitasking and context switching. And they are challenging college to change its education effort, traditionally anchored in the development and presentation of content. That is, making it more easily accessible, via the web and open contents [6].

Cognitive scientists have come to the conclusion that, perhaps, the best approach in these technological environments is to keep the student free, letting him/her set his/her own learning environments. New pedagogies, such as peer-to-peer learning, content development and the use of massively multiplayer games ("virtual worlds") as a simulation tool are rapidly replacing faculty as the dominant educational process in several technology-rich fields. In these new learning paradigms, the word "student" becomes largely obsolete, because it describes the passive role of absorbing selected content transmitted by teachers. Instead, we should probably start referring to the 21st-centrury university "costumers" as active learners. In addition, our students will seek less to learn about something and, instead, will seek to "learn to be" looking for opportunities to experience the thrill and challenge of engineering practice [7]. In a similar sense, the concept of a teacher as one who develops and presents the knowledge to students, largely passive, can become obsolete too. These new paradigms' role is to encourage and guide active learning. In other words, to inspire, motivate, manage and train students.

Directed to the guidance of personal rediscovery, the development of practical activities came to have a strong presence in projects in education and training courses for teachers in the 1970s. Nowadays, more than 30 years after, one cannot say that the scientific method has been effectively applied on a large scale in Brazil. Indispensable conditions, like laboratories and mediators' training, have not been established. In the few schools where there are labs, students just mechanically reproduce the experimental procedures in order to solely reach the error bound — which was previously established — to the measured quantity. This culminates making the student lose the opportunity to work with students, their natural curiosity to the phenomenon observed, the motivational aspects, the extensive variety of possibilities in the experiment and the appropriate processes to problematize research raised by every scholar.

It is evident that the change will require an engineering education increasingly distant from the theoretical, expository and abstract method, and a laboratory for experiments in a more active way of learning, involving problem solving skills, team building, creativity, design and innovation. But these concerns are neither new nor unique to engineering education. Psychologists and cognitive scientists have known for decades that the most effective learning takes place through active discovery and the application of knowledge, rather than mere study and contemplation. From John Dewey to Jean Piaget, we have ample evidence that most students learn better by "constructivist learning". However, classes with limited time in the lab and lack of practices prevail in Brazilian education. In addition, the lack of skill in written expression when representing ideas also implies a debate on 
the need for semiotic and iconic of conducting the experiments [8].

The requirements to form citizens capable of critically acting in contemporary society have also changed. Consequently, the educational system has been compelled to modify, yielding numerous challenges for education professionals seeking to exploit modern technology in their teaching. The proper use of ICT can result in quantitative and qualitative differences in school work-for teachers and students-and in the academic environments. In this paper, we describe some activities in which ICT leads to a class of basic-cycle engineering (physics), readjusting the pedagogical idea for a school that has been reconfigured by digital technology.

Thus, the goal of this work is to highlight the exploratory and experimental nature of the scientific methodin its constitutive elements and steps-as a technical-pedagogical path that leads the student to the discovery of processes and phenomena, while powered by its own personal rediscovery. In this context, the laboratory, which is expanded and enriched in opportunities by ICT, is the bedrock. Such model implanted in classrooms signifies the conceiving of the pedagogical method in a new way, combining it with the scientific method.

\section{A Profile of the Classroom}

The paradigm found in the traditional classroom is being put in check nowadays, not so much by teachers who have, in general, their teaching efforts optimized for a lecture format, but by the students. Students have been born into a digital world and are comfortable with these technologies in a way that older people (including, their teachers) will never be. Students, members of the digital generation, have spent their entire lives immersed in electronic games, video media, personal computers, cellular phones, instant messengers, etc. Unlike those of us who were raised in an era of passive media, whose agents were radio and television broadcasts, today's students actually look for interaction. They approach learning as a "plug-and-play" experience and are not accustomed to (nor willing to) learn by reading a printed textbook. Instead, they are inclined to dive in and learn through participation and experimentation.

Although this type of learning is very different from the sequential approach and traditional pyramidal university curriculum, it seems to be much more effective for this generation, particularly when provided through a media-rich environment.

While studying this generation's learning habits, John Seely Brown and his colleagues at Xerox PARC identified several interesting characteristics of the learning process [7]. First, today’s students do several things at the same time: they are "multitasking", performing several tasks simultaneously on a computer, such as web surfing and emailing while listening to music or talking on a cell phone. Despite their attention span seem to be short; since they jump from one activity to another constantly, they seem to learn with the same efficacy as that of previous generations. They mastered the ability of fast context switching, a key ability in our present world. Moreover, they also master a wide range of literacy skills, extending the traditional verbal language with visual images and hypertext links. They are particularly adept at navigating through complex arrays of information, acquiring knowledge resources that build sophisticated networks of learning resources.

Today's students are active learners. They construct their own knowledge structures and learning environments through interaction and collaboration. Also, they approach learning in a non-linear way rather than following the sequential structure of the typical college curriculum and confront the traditional learning methodology through the development and presentation of content, which is easily accessible through the web and through open content, in a new methodology in which the teacher's becomes a mentor and a consultant to learning [6].

There is still no consensus among teachers about the future of education, but there is a strong and widespread belief that the "Internet" generation is changing the learning process in its structure. In these new learning paradigms, the word "student" as we conceive it becomes obsolete, mainly because it describes the passive role of absorbing the previously selected content transmitted by teachers. Individuals who attend to the University of the 21st century are active learners, since they require more and more responsibility and autonomy in their own learning experiences and outcomes. In addition, our students will not look forward to "learning about something" (after all, in many ways, they are more sophisticated in navigating knowledge in the digital age than their teachers, so they can find the information they need much easily) and, instead, look forward to "learning to be", seeking opportunities to experience the engineering practice as a real engineering trainee.

Universities will be pressed to no longer center institutions in college, where it is determined what to teach, whom to teach, how to teach, where to teach and when to teach. Instead, universities will likely evolve to be 
learner-centered institutions, where students have many more options and control over what, how, when, where and with whom to learn. This should not surprise us since, in an increasingly democratic and market-oriented world, the concerns of individuals and clients are extremely important. Indeed, it is seen that clients have become the main focus in most successful organizations.

As we have already mentioned, at several years ago, the development of practical activities came to have a strong presence in educational projects and training courses for teachers in Brazil, having originated instructional materials that document this trend. At that time, the primary goal of teaching natural science was to allow the students to experience what is termed scientific method: from comments, they raised hypotheses that were tested and, finally, endorsed or refuted. Later, that was abandoned, which should give rise to new formulations continuing the search for a solution to the research problem.

The experimental lesson should not be seen only as a demonstration of the theory seen in the classroom. Actually, it is essential that the science teacher use it as an important tool to stimulate not only learning, but also the reasoning and teamwork, developing skills not ordinarily raised in a theoretical lecture.

The classroom in which observations and experimentations occur should be eminently interactive. In it, the student's participation occurs in potential states of knowledge presented by the teacher, and evolves the necessary openness to the diversity of opinions, instability and randomness of interest. In this environment, the student doesn't simply look, listen and copy, he thinks, modifies and constructs, thus, becoming coauthor of knowledge production.

The model has the following characteristics: context should satisfy the curiosity of the student before the observed phenomenon; the everyday experiences must be coupled with experiences in conducting; the activity is social because it is developed in groups, in general; practical activities should stimulate the interest and, possibly, the vocation of the student to the sciences; the student becomes the author of their learning.

This paradigm brings a new meaning to the pedagogical method, combining it with the scientific method. The didactic-pedagogic methodology is then provided with the requirements that have been identified as facilitators of learning by several authors, among them [9]-[12].

The engineering colleges should create learning environments oriented to the discovery that take advantage of the power of new information, communication and visualization technologies [1]. However, limited time in the lab, in practices, prevail in science education. This has negative effects on the newly formed professionals: prejudicing their productivity, their ability to create and innovate, and, ultimately, limiting their opportunities of insertion in the professional environment.

Engineering schools have strong evidence of the efficacy presented by constructivist learning through results of several studies and competitive projects among students [1]. Educators should strive to create such immersive experiences for engineering students in an effort to teach them not only the "how to", but, more importantly, the "how to be" [7].

\section{ICT and the Classroom}

According to Alves [3], the possibilities of access to information and systematized knowledge, as well as the interactions between different educational subjects, have expanded significantly. The use of information and communication technology (ICT) is changing the model of social life drastically. New forms of organization, production of goods, trade, leisure, education and learning are emerging. The requirements to form citizens capable of acting critically in contemporary society have also changed. A true technological arsenal is available and has been incorporated into the daily activities of people, regardless of social class and age. Consequently, the educational system has been compelled to modify, yielding numerous challenges for education professionals that seek to exploit modern technology in their teaching, although, in general, ICTs just represent new ways to perform tasks that already found in classes.

Without depreciating these innovations, which can raise the interest and motivation of the student, ICT can reformulate the strategies of teaching and learning, exploring, in particular, the immediate access to communication and information. There is a current debate about resources that present great potential and that are increasingly more accessible to teachers and students, in education, research institutions and in their homes. The proper use of ICTs can result in quantitative and qualitative enhancement in school work-for teachers and students - and in academic environments, provided that excesses and minutiae, as well as problems raised by the use of equipment and digital processes, are handled accordingly. As noted by Pelgrum and Law [13], the diver- 
sification of educational resources and the integration of ICTs in education lie in teachers highlighting the importance of their development and knowing how to exploit these new tools in the best way possible.

In this paper, we describe some activities in which ICT is applied to a basic-cycle engineering class, in this case, a chemical one. That allows changes in a school's pedagogical proposal, reconfigured by digital technology.

\section{The Proposed Methodology}

The method suggested here is not exactly a novelty, since practice and computer simulation classes are well known by the greater part of educators. However, few of them use any of these resources in their engineering classes. It should be clarified that this methodology is not targeted for training scientists, or performing a precise scientific measurement, but for exploring accessible teaching resources (as stimulators), reaching the conceptualization of the phenomenon being studied. The difference in this suggestion is revisiting the scientific method and the reframing of ICT, as they cease to be new ways to perform old activities and become tools that, in addition to accessing to information, facilitate conducting experiments at times it is not possible to use a lab. Such approach creates an interactive lesson, using new tools and bringing to reality a new didactic-pedagogic model, no longer restricted to merely "bookish" education.

The experiment makes it possible for individuals to manipulate objects and ideas, discuss their meanings with peers and with the teacher during class and share knowledge in the discussion of the observations and results. The scientific methodology allows the development of capacity and autonomy of thinking. Scientific behavior enables activities that require adapting, modifying, reordering, exchanging ideas and situations and, finally, overcoming obstacles, transcending mere impressions.

Many ICT's are able to model human cognitive functions. As noted by [12], these "intellectual technologies" favor new forms of accessing information and new styles of reasoning and knowledge, such as simulations, a kind of experiment derived from the experience, belonging neither to logical deduction nor induction. The simulation comes to occupy a prominent place in teaching and learning because the manipulation of different parameters allows you to try different variables in real-world situations, providing commands that help establishing relations in proportion, time, temperature, and other critical concepts to a better comprehension and the use of language of chemical engineering aspects. In what follows we discuss a usual example.

In chemical kinetics, we study the rates of chemical reactions as well as the factors that influence these speeds. In this area, what do matters are the intermediate stages of the chemical process. The rate of reaction depends on the concentration of the reactants. This can be explained by the theory of collisions, since the higher the concentration of the participating reactants, the greater the probability of having collision between reacting species, thus increasing the rate of chemical reaction. Another factor that influences the rate of a chemical reaction is the temperature. The temperature greatly influences the rate of chemical reactions. The increased temperature not only increases the frequency of collisions between reactant molecules, but also the energy with which collisions occur, increasing the speed of the chemical process.

One way to analyze the factors that influence the speed of reaction is by using the Arrhenius equation, from which one can calculate the rate constant $k$ at a particular temperature. One way to analyze the factors that influence the speed of reaction is by using the Arrhenius equation, from which one can calculate the rate constant $\mathrm{k}$ at a particular temperature. The Arrhenius equation is well known and it shows the dependence of the logarithm of the constant $k$ with the reciprocal of temperature $(1 / T)$ as linear and decreasing.

A usual classroom work is to experimentally determine the effect of temperature on the reaction rate, the activation energy and the frequency factor's of the reaction between sodium hydrogen sulfite and potassium iodate. In this way, the students raise the curves and observe the slope of the straight line.

Simulations represent reality based on mathematical models, with which, through a user-friendly interface (Figure 1), the individual may change the model and modify the simulation to meet its general and specific objectives, either in the seizure of concepts, or the relation between magnitudes using graphs and references. A mathematical model is a simplification of reality that seeks to understand a real situation. It is a metaphor that constructs the underlying meaning for natural phenomena. The rigor and the level of realism of graphical representations from the use of simulations, minimizes the effort of abstraction inherent to some content of science subjects.

To simulate the reaction rates, we have used a freeware called "Modellus” (although the Matlab may be used 


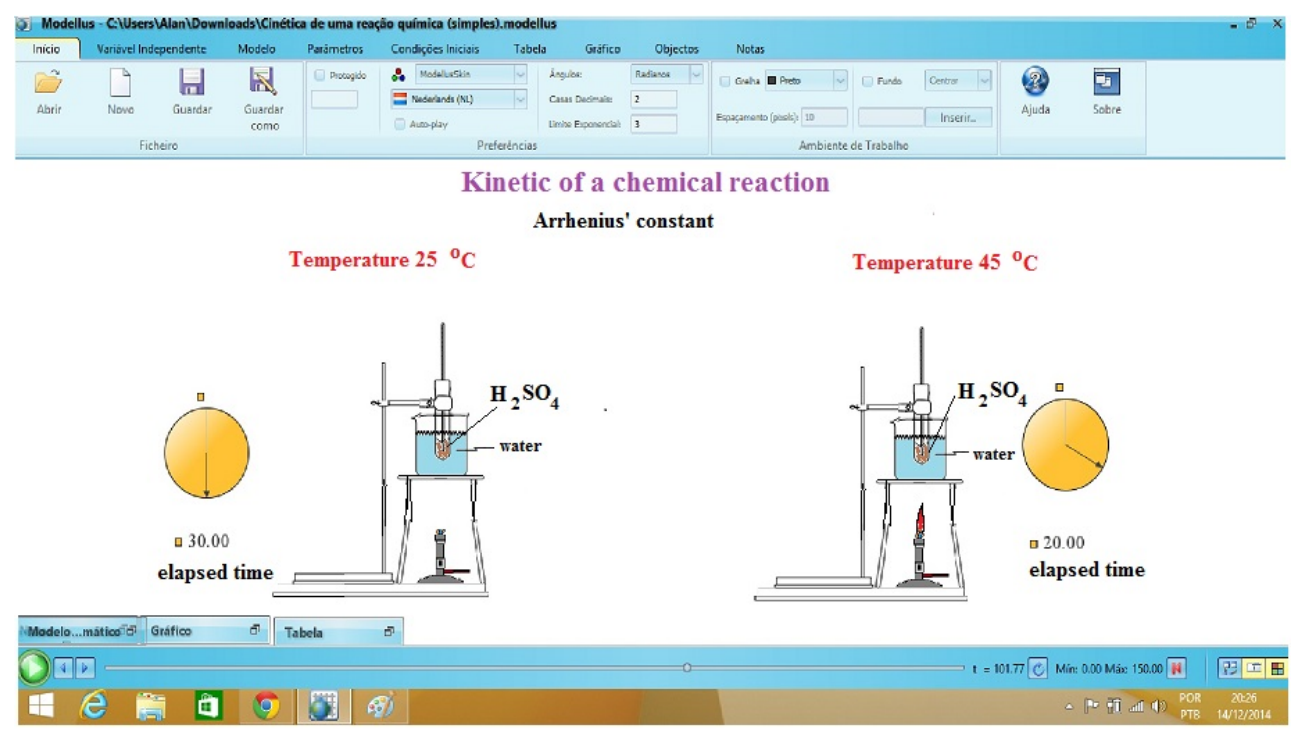

Figure 1. Modellus interface while simulating the reaction rates.

too [14]) in order to calculate the elapsed time and the activation energy. Trying to represent dynamic models through static pictures (as in the books, and most of the classes) requires the viewer a great capacity for abstraction, what most students do not have, and whose absence leads to uninterested students and, possibly, to rote learning [15]. Therefore, the simulations are powerful teaching tools when combined with the explanation of phenomena, making the process of learning more effective. The student doesn't need to imagine the phenomenon's dynamics, since he observes the event, resulting in a meaningful learning.

The model may be applied in the simulation at different levels. For example, it may include concentration of the reactants, molecular collisional rates, non-linear effects, and so on. This whole set of information provides tremendous flexibility for lesson content, and it can all be performed in real time, in the virtual lab.

In an interactive lecture, several questions may arise and various topics can be discussed, such as: "What happens to the reaction rates if the value of some parameter ( $T$, activation energy, or collisional factor) is changed?” Also, many other topics can be discussed, such as vaporization limit, molecular collisional rates, other reactants, new concentrations, etc. The limit of the experience is the curiosity of the class and the class duration that, in such an environment, is always too short.

\section{Conclusions}

The resumption of the scientific method for teaching and pedagogical activities is aimed to rescue the practice of experimentation, nowadays enriched by the possibility of computer simulation. The use of ICT-related activities which were organized according to the scientific method is a response to the demands of a society framed by the technological, scientific and sociocultural evolution. In a globalized world, where information and scientific knowledge circulate freely and quickly through the network, it provides a deeper development of the individual ability of deciding or choosing, from select routes and paths, one that fits their more own learning, since, as Hargreaves (2003) asserts, the knowledge society is a community of learning and teaching activities should enhance it.

The new contextualization of scientific method in their assumptions and their use in teaching practice is a proposal focusing on the implementation of the experimental/practical activities and use of ICT. This methodology allows the discussion of content to explain the world and give opportunities to the individual to acquire/develop capabilities to operate in this world. Although the subject discipline has been engineering, discussions supported by a critical and reflective attitude apply to most (if not all) of human experiences.

\section{Acknowledgements}

This research was supported in partby Fundação Carlos Chagas Filho de Amparo à Pesquisa do Estado do Rio 
de Janeiro—FAPERJ, Brazil and Fundação de Amparo a Pesquisa do Estado do Amazonas—FAPEAM, Brazil.

\section{References}

[1] NSB (2007) Moving Forward to Improve Engineering Education, ad hoc Task Group on Engineering Education, Committee on Education and Human Resources, Draft Report, July 23, 2007. National Science Foundation, Washington.

[2] Bordogna, J., et al. (1993) Engineering Education: Innovation through Integration. Journal of Engineering Education, 38.

[3] Alves, G. (2006) A produção da Escola Pública Contemporânea. Autores Associados, Campinas.

[4] Brown, J.S. (2006) New Learning Environments in the 21st Century. Futures Forum, Aspen, CO: Futures Project, 2005; also MIT Symposium on iCampus, December 2006.

[5] Duderstadt, J.J., et al. (2005) Cyberinfrastructure. A Special Issue of Issues in Science and Technology, Vol. XXII, No.1. National Academies Press, Washington.

[6] Dweck, C., et al. (2007) Implicit Theories of Intelligence Predict Achievement Across an Adolescent Transition: A Longitudinal Study and an Intervention. Child Development, 78, 246-263.

[7] Hargreaves, A. (2003) Teaching in the Knowledge Society: Education in the Age of Insecurity. College Press, NY.

[8] Simões, D. (2002) Linguagem e expressão no ensino de Física. Caderno Seminal, 14, 109-124.

[9] Marchesi, A. and Martín, E. (2003) Tecnología e aprendizaje. Editorial SM, Madrid.

[10] Moran, J.M. (2009) Especialista em projetos inovadores na educação presencial e a distância. In: Moran, J.M., Eds., Novas Tecnologias e Mediação Pedagógica, Papirus, São Paulo, 15th Edition, 22-24.

[11] Moreira, M.A. (1999) Aprendizagem Significativa. Editora Universidade de Brasília, Brasília.

[12] Abbott, J. (2004) We Are a Small Group Species. Source: 21st Century Learning Initiative. http://changelearning.ca/articles/we-are-small-group-species

[13] Pelgrum, W. and Law, N. (2003) ICT in Education around the World: Trends, Problems and Prospects. UNESCO-IIEP, Paris.

[14] Silva, C.E., Santiago, A.J., Machado, A.F. and Assis, A.S. (2014) Eletromagnetismo: Fundamentos e simulações. Pearson Education do Brasil, São Paulo.

[15] Simões, D. and García, F. (Orgs.) (2014) A Pesquisa Científica como Linguagem e Práxis. Dialogarts, Rio de Janeiro. 